\title{
Food insecurity in Nunavut following the introduction of Nutrition North Canada
}

\author{
Andrée-Anne Fafard St-Germain RD, Tracey Galloway PhD, Valerie Tarasuk PhD
}

Cite as: CMAJ 2019 May 21;191:E552-8. doi: 10.1503/cmaj.181617

See related article at www.cmaj.ca/lookup/doi/10.1503/cmaj.190497

\begin{abstract}
BACKGROUND: Household food insecurity, a measure of income-related problems of food access, is a pressing public health problem in Canada's North, especially in Nunavut. We aimed to assess the impact of Nutrition North Canada, a food retail subsidy intended to improve food access and affordability in isolated communities, on household food insecurity in Nunavut.
\end{abstract}

METHODS: Using data from 3250 Nunavut households sampled in the annual components of the Canadian Community Health Survey (2007 to 2016), we conducted interrupted time series regression analyses to determine whether the intro- duction of Nutrition North Canada was associated with changes in the rates of self-reported food insecurity, according to a validated instrument. We used propensity score weighting to control for several sociodemographic characteristics associated with food insecurity.

RESULTS: Food insecurity affected $33.1 \%$ of households in 2010 (the year before the launch of Nutrition North Canada), 39.4\% of households in 2011 (the year of the launch) and $46.6 \%$ of households in 2014 (the year after full implementation). After controlling for several covariates, we found the rate of food insecurity increased by 13.2 per- centage points ( $95 \%$ confidence interval [CI] 1.7 to 24.7) after the full implementation of the subsidy program, and the increase in food insecurity first occurred in 2011 (9.6 percentage points, 95\% Cl 2.7 to 16.4$)$, the year Nutrition North Canada was launched.

INTERPRETATION: Food insecurity was a pervasive problem in Nunavut before Nutrition North Canada, but it has become even more prevalent since the program was implemented. Given the important health consequences of food insecurity, more effective initiatives to address food insecurity in Canada's North are urgently needed.
$\mathrm{H}$ ousehold food insecurity, defined as insecure or inadequate access to food because of financial constraints, is increasingly recognized as a serious public health problem in many affluent nations. ${ }^{1-4}$ The latest national estimate for Canada indicates that $12.6 \%$ of households experienced food insecurity in $2012,{ }^{5}$ but important geographic variations exist within the country, with heightened vulnerability in the North. ${ }^{5-7}$ Since national monitoring began, Nunavut has consistently had the highest rates of food insecurity, ${ }^{5,6,8}$ with the rate reaching $46.8 \%$ in $2014 .{ }^{8}$ Food insecurity is strongly associated with poor nutrition ${ }^{9-13}$ and adverse mental and physical health outcomes across the life cycle. ${ }^{14-22}$ Recent research also indicates that food insecurity is a robust and independent predictor of increased health care use ${ }^{23}$ and expenditures. ${ }^{24,25}$

Food insecurity represents an experience of material deprivation strongly influenced by the economic resources of households, ${ }^{26-30}$ but high food prices are also considered an important driver of food insecurity in Canada's North., ${ }^{731-34}$ In April 2011, the Government of Canada replaced the long-standing Food Mail
Program with Nutrition North Canada, a market-driven food retail subsidy intended to make perishable, nutritious foods more affordable and accessible in northern communities that do not have year-round rail, road or marine access. ${ }^{34-36}$

Similar to the Food Mail Program, Nutrition North Canada serves communities that are predominantly inhabited by Indigenous Peoples and have high rates of food insecurity, low educational attainment, low income, underemployment and unemployment. ${ }^{34,37,38}$ Whereas the Food Mail Program consisted of an air freight transportation subsidy transferred to Canada Post for the delivery of numerous perishable foods, nonperishable foods and essential nonfood items, ${ }^{35,37,39}$ Nutrition North Canada is a retail subsidy focused primarily on perishable, nutritious foods and transferred directly to southern suppliers and northern retailers, who are expected to pass on the full subsidy to consumers at the point of purchase ${ }^{35,40}$ (a summary of the programs is provided in Appendix 1, Supplemental Table A1, available at www.cmaj.ca/lookup/suppl/doi:10.1503/cmaj.181617/-/DC1). 
Nutrition North Canada follows a market-driven approach predicated on the assumption that giving full control to retailers and suppliers over the supply chain and relying on market competition can reduce the prices of subsidized foods more effectively. ${ }^{35,40}$ The program's focus on perishable, nutritious foods and its market-driven approach were strategies adopted to help contain program costs. ${ }^{34,35}$ Nutrition North Canada also includes a small nutrition-education component, ${ }^{35,40}$ and it is assumed that reductions in the prices of perishable, nutritious foods coupled with nutrition education will improve northerners' food access. ${ }^{40}$ Although Nutrition North Canada does not explicitly aim to reduce food insecurity, the pervasiveness of food insecurity in the North is embedded in the rationale for the program..$^{34,38}$

Our objective was to assess the impact of the introduction of Nutrition North Canada on household food insecurity in Nunavut communities.

\section{Methods}

\section{Data source and sample}

Data were obtained from the annual components of the Canadian Community Health Survey from 2007 to 2016, a repeated, cross-sectional, population-based survey administered by Statistics Canada to collect health-related information. ${ }^{41}$ The survey covers individuals aged 12 years and older in all provinces and territories, except for full-time members of the Canadian Forces, those living in institutions, those living in 2 northern health regions in Quebec, and people living on reserves or other Indigenous settlements in the provinces. ${ }^{41}$

This study used data from households living in the 10 largest communities of Nunavut (Iqaluit, Rankin Inlet, Cambridge Bay, Kugluktuk, Cape Dorset, Pangnirtung, Igloolik, Pond Inlet, Baker Lake and Arviat), the only communities eligible for Nutrition North Canada included in the Canadian Community Health Survey from 2007 to 2016. These communities are predominantly inhabited by Inuit people, and they account for about 30\% of the total population of the 84 communities eligible for the full subsidy, receiving nearly one-third of the annual subsidy budget and annual volume of food subsidized from 2011 to $2016 .^{36}$

\section{Measure of household food insecurity}

Food insecurity over the past 12 months was assessed using the 18-item Household Food Security Survey Module, a validated scale used for monitoring in Canada and the United States. ${ }^{6,42-44}$ The scale measures food access problems that range in severity from worrying about running out of food to compromising on the quality of food purchased, to eating less or going a whole day without eating because there was not enough money to buy food. ${ }^{1,5}$ Because a single affirmative response to the module represents an experience of marginal food insecurity associated with adverse health outcomes, ${ }^{20,21,23,24}$ households with 1 or more affirmative responses were considered food insecure, and households with no affirmative response were considered food secure. Households that answered none of the items were coded as missing and excluded from the analysis $(n=62)$. To minimize the loss of sample size, the $3 \%$ of households with some missing items were classified as food secure or food insecure based on their responses to nonmissing items, ${ }^{45}$ with $85 \%$ classified as food insecure.

\section{Statistical analysis}

We used interrupted time series analysis, a quasi-experimental study design, ${ }^{46,47}$ to assess whether the introduction of Nutrition North Canada affected rates of food insecurity. Given that interrupted time series analysis is sensitive to time-varying confounders, ${ }^{46,47}$ propensity score weighting ${ }^{48}$ was used to control for macroeconomic trends and ensure that the annual samples were comparable on sociodemographic and economic variables known to be associated with food insecurity but unrelated to the introduction of Nutrition North Canada, such as household structure, income and education. We also included a variable identifying survey respondents younger than 18 years to account for the 2015 change in the sampling frame for Nunavut. ${ }^{41}$ The 2007 survey year was set as the reference, meaning that the sample for each subsequent year was weighted to have the covariate profile of the 2007 sample. Logistic regression models were used to estimate a propensity score for each household; the weight was set to 1 for households interviewed in 2007 or calculated as the propensity score divided by 1 minus the propensity score for all other households. ${ }^{48}$ The application of the weights resulted in covariate balance across all survey years. We used the weights to estimate annual propensity score-weighted rates of food insecurity, the dependent variable in the models.

In Appendix 1, Supplemental Figure A1 presents a timeline of the implementation of Nutrition North Canada, with the survey years and periods included in the 2 impact models that were tested. The first impact model tested whether there was a change in the trend and level of food insecurity after the full implementation of the program. The model included 2 segments, the periods before the launch of Nutrition North Canada (20072010) and after its full implementation (2014-2016). The years of implementation (2011 and 2012) with a lag period (2013) were excluded from this model. A 1-year lag was included because food insecurity is measured for the past 12 months, and a reduction in food insecurity would be detected 12 months after implementation. The second impact model tested whether the launch of Nutrition North Canada in 2011 was associated with changes in food insecurity and included 3 segments representing the periods before the launch, during implementation with the 1-year lag and after full implementation. Owing to multicollinearity, the second impact model tested for a change in trend after the launch but not after full implementation; the latter change was tested in the first impact model. We conducted linear regression models with robust standard errors to estimate the impact models. The trends within each segment were assumed to be linear. ${ }^{46,47}$ The time unit of analysis was survey year, with 7 time points in the first impact model and 10 in the second impact model. Based on the Durbin-Watson statistic, there was no firstor second-order autocorrelation. ${ }^{49}$

To respect Statistics Canada's confidentiality requirements, sample sizes and cell counts for the covariates were rounded to the nearest 10 for presentation. The significance level was set at $p<0.05$. All analyses were performed with Stata statistical software, version 15. 
To determine whether negative macroeconomic shocks occurred in Nunavut when Nutrition North Canada was introduced, we visually inspected time trends for several macroeconomic factors associated with food insecurity ${ }^{30,50-52}$ (Consumer Price Index, social assistance caseload, gross domestic product, and rates of low income and unemployment) (Appendix 1, Supplemental Figure A2).

\section{Ethics approval}

This study is part of a research project that received ethics approval from the Human Research Ethics Board of the University of Toronto.

\section{Results}

The analytic sample included 3250 Nunavut households with a measurement of food insecurity, and the annual sample sizes ranged between 260 and 380 .

The annual rates of food insecurity ranged between $33.1 \%$ and $40.0 \%$ before the launch of Nutrition North Canada, between $39.4 \%$ and $45.7 \%$ during the implementation and 1-year lag, and between $46.0 \%$ and $55.6 \%$ after the full implementation (Figure 1A). Overall, food insecurity affected $33.1 \%$ of households in 2010 (the year before the launch of Nutrition North Canada), $39.4 \%$ of households in 2011 (the year of the launch) and $46.6 \%$ of households in 2014 (the year after full implementation).

Based on the visual inspection of trends over time, we identified no sudden macroeconomic change that coincided with the introduction of the program (Appendix 1, Supplemental Figure A2). Table 1 presents the distribution of the covariates for the 3 periods used in the impact models. Covariate imbalances were present in the unweighted sample, but these were addressed with the application of the weights (Appendix 1, Supplemental Table A2). The weighted rates of food insecurity used in the models were generally lower than the original rates and had less year-to-year variation (Figure 1A).

The first impact model showed that the trends in the annual rates of food insecurity were constant during the period before the launch of Nutrition North Canada $(-1.7 \%$, 95\% confidence interval $[\mathrm{Cl}]-5.7 \%$ to $2.2 \%$ ) and the period after its full implementation $(0.0 \%, 95 \% \mathrm{Cl}-6.1 \%$ to $6.1 \%)$, with no significant trend change between the 2 periods $(1.7 \%, 95 \% \mathrm{Cl}-5.5 \%$ to $9.0 \%)$ (Table 2 and Figure 1B). However, the rate of food insecurity immediately after implementation was 13.2 percentage points (95\% $\mathrm{Cl} 1.7$ to 24.7 ) higher than the rate just before the launch. This means that the rate of food insecurity after implementation was $43 \%$ higher than the rate expected if the trend before the launch had continued. The second impact model indicated that the rate of food insecurity increased by 9.6 percentage points (95\% Cl 2.7 to 16.4 ) in 2011, the year Nutrition North Canada was launched (Table 2 and Figure 1C). This means that the rate of food insecurity was $31 \%$ higher than the rate expected if the trend before the launch had continued. There was no significant trend change between the periods before the launch and during implementation. The trend in food insecurity rates during the years of implementation was constant.

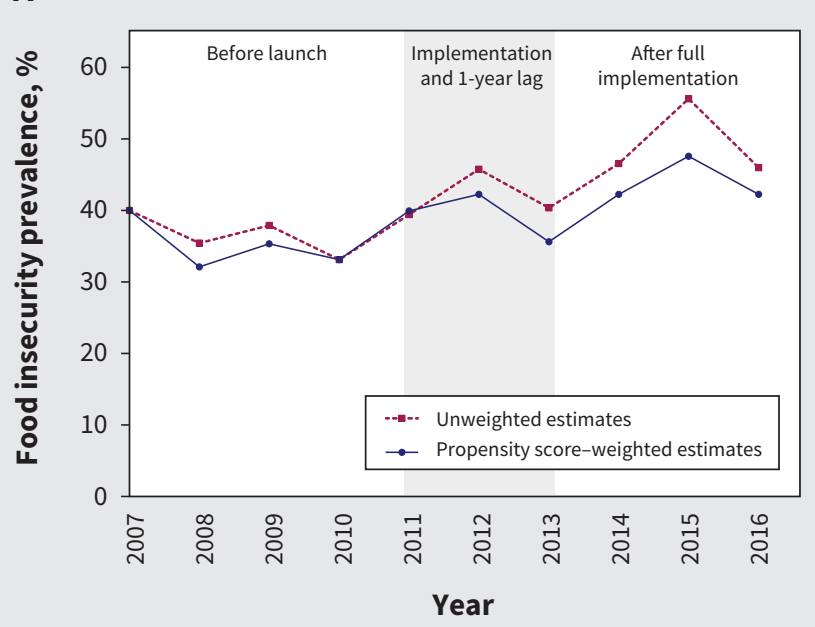

B

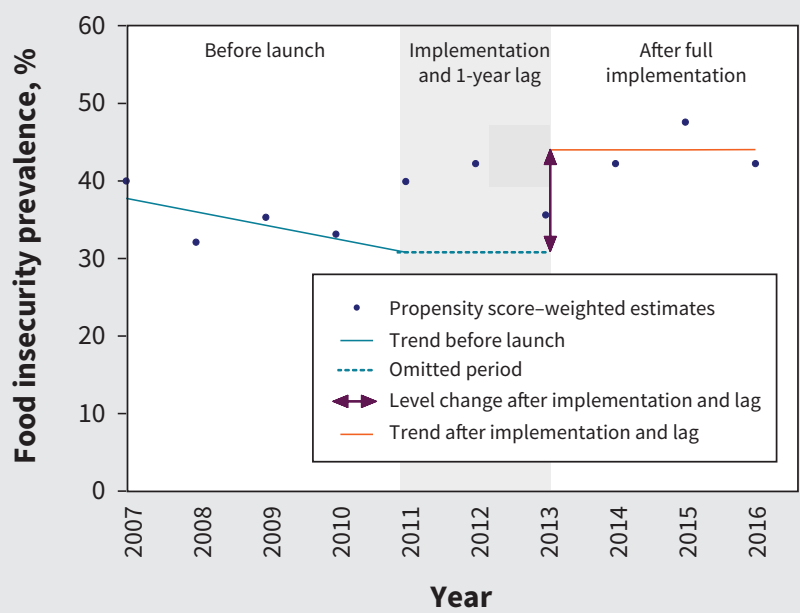

C

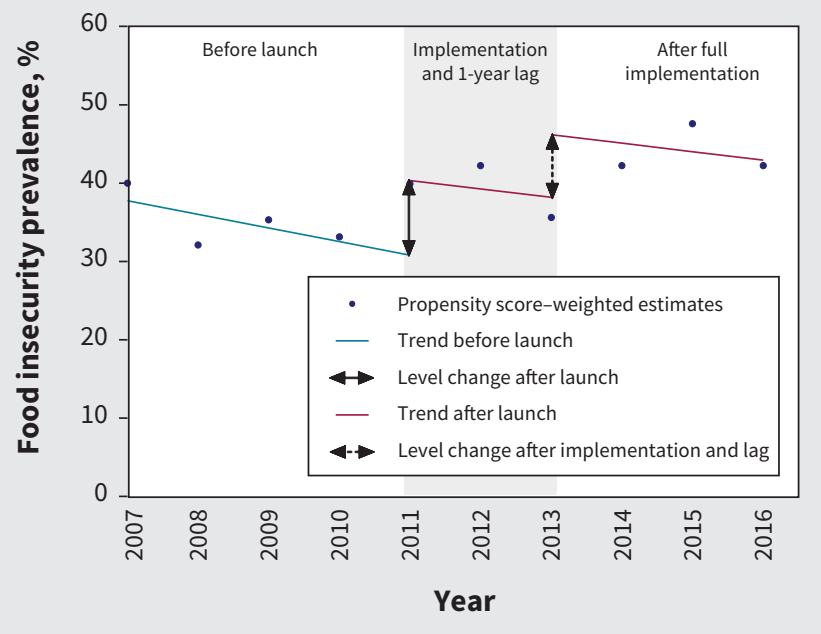

Figure 1: (A) Unweighted and propensity score-weighted prevalence estimates of food insecurity from 2007 to 2016, and changes in the trend and level of food insecurity (B) after the full implementation (impact model 1) and (C) after the launch of Nutrition North Canada (impact model 2). 
Table 1: Distribution of covariates in the original, unweighted sample of households in Nunavut before the launch of Nutrition North Canada, during implementation with a 1-year lag and after full implementation

\begin{tabular}{|c|c|c|c|c|c|}
\hline \multirow[b]{2}{*}{ Covariate } & \multicolumn{4}{|c|}{$\%$ of households* } & \multirow[b]{2}{*}{$p$ valuet } \\
\hline & $\begin{array}{c}\text { Total sample } \\
(2007-2016) \\
n=3250\end{array}$ & $\begin{array}{c}\text { Before launch } \\
(2007-2010) \\
n=1360\end{array}$ & $\begin{array}{c}\text { Implementation } \\
\text { with 1-year lag } \\
(2011-2013) \\
n=990\end{array}$ & $\begin{array}{c}\text { After full } \\
\text { implementation } \\
(2014-2016) \\
n=900\end{array}$ & \\
\hline \multicolumn{6}{|l|}{ Household type $\ddagger$} \\
\hline Couple without children & 11 & 12 & 12 & 9 & 0.08 \\
\hline Couple with children§ & 48 & 47 & 46 & 51 & 0.1 \\
\hline Single person & 24 & 25 & 25 & 24 & 0.9 \\
\hline Single female parent§ & 12 & 12 & 12 & 12 & 0.9 \\
\hline Other & 5 & 4 & 5 & 5 & 0.7 \\
\hline Presence of child $<18 \mathrm{yr}$ & 59 & 58 & 56 & 62 & 0.02 \\
\hline Respondent identified as Inuit & 71 & 71 & 71 & 71 & $>0.9$ \\
\hline Household income, $₫$ mean \pm SD, \$ & $49015 \pm 47325$ & $46895 \pm 40795$ & $51320 \pm 49165$ & $49690 \pm 53940$ & 0.06 \\
\hline Household income $\leq$ LIM & 37 & 35 & 38 & 38 & 0.2 \\
\hline Imputed household income & 33 & 33 & 31 & 37 & 0.04 \\
\hline \multicolumn{6}{|l|}{ Main income source } \\
\hline Wage, salary and self-employment & 75 & 76 & 75 & 72 & 0.1 \\
\hline Social assistance & 10 & 10 & 9 & 12 & 0.2 \\
\hline Other & 15 & 14 & 16 & 16 & 0.3 \\
\hline Any social assistance ${ }^{\star \star}$ & 23 & 20 & 21 & 29 & $<0.001$ \\
\hline Any employment insurance ${ }^{\star \star}$ & 8 & 6 & 8 & 10 & $<0.001$ \\
\hline Any seniors' income ${ }^{\star \star}$ & 11 & 11 & 12 & 8 & 0.001 \\
\hline \multicolumn{6}{|l|}{ Highest household education } \\
\hline Less than high school & 20 & 18 & 22 & 20 & 0.07 \\
\hline High school completed & 14 & 13 & 16 & 14 & 0.2 \\
\hline Postsecondary completed & 56 & 56 & 54 & 58 & 0.2 \\
\hline Missing & 10 & 13 & 8 & 8 & $<0.001$ \\
\hline Household owns dwelling & 27 & 28 & 26 & 27 & 0.5 \\
\hline Respondent aged $<18 \mathrm{yr}$ & 14 & 15 & 15 & 12 & 0.08 \\
\hline \multicolumn{6}{|c|}{ 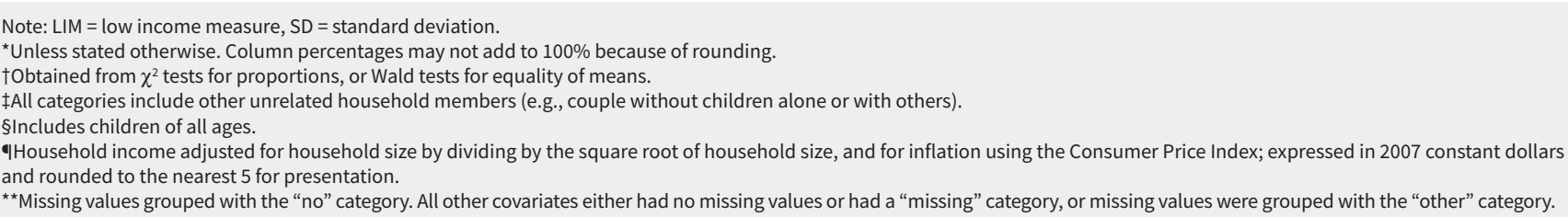 } \\
\hline
\end{tabular}

\section{Interpretation}

We found that the prevalence of food insecurity rose after the implementation of Nutrition North Canada and that the rise in food insecurity first occurred in 2011, the year that the program was launched. One potential explanation for the worsening food insecurity may be the program's focus on perishable, nutritious foods and the exclusion of most nonperishable foods and all nonfood items from the subsidy. ${ }^{34,35,39}$ These exclusions may have prevented households from improving their access to food and, in some cases, worsened their access to food, insofar as the prices of common nonperishable foods and essential items rose.

There are some reports that the launch of Nutrition North Canada coincided with a rise in the prices of some nonperishable foods and household items in participating communities in northern Quebec, ${ }^{34,35}$ but the lack of systematic price monitoring for items that lost eligibility for subsidy precludes examinations of price changes in the communities included in this study. ${ }^{53} \mathrm{Nev}$ ertheless, our study adds to previous critiques of Nutrition North 
Table 2: Results from the interrupted time series analyses assessing changes in food insecurity after the full implementation (impact model 1) and the launch (impact model 2) of Nutrition North Canada

Estimate, $\%(95 \% \mathrm{Cl})$

\section{Variable}

Base level

Trend in annual rates before launch

Level change after launch

Change in the trend after launch

Trend in annual rates after launch

Level change after implementation and 1-year lag

Change in the trend after implementation and 1-year lag

Trend in annual rates after implementation and 1-year lag

\section{Impact model $1^{\star}$}

30.8 (24.1 to 37.5$)$

$-1.7(-5.7$ to 2.2$)$

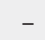

$-$

13.2 (1.7 to 24.7 )

$1.7(-5.5$ to 9.0$)$

$0.0(-6.1$ to 6.1$)$
Impact model $2 \dagger$

30.8 ( 25.8 to 35.8$)$

$-1.7(-4.7$ to 1.2$)$

9.6 (2.7 to 16.4$)$

$0.7(-4.0$ to 5.3$)$

$-1.1(-4.7$ to 2.5$)$

$8.0(-8.2$ to 24.2$)$

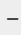

Note: $\mathrm{Cl}=$ confidence interval.

${ }^{*}$ Impact model 1 tested whether there was a change in the trend and level of food insecurity after the full implementation of Nutrition North Canada compared with before the launch of the program.

IImpact model 2 tested whether there was a change in the trend and level of food insecurity after the launch of Nutrition North Canada compared with before the launch of the program.

Canada ${ }^{53-57}$ by showing that food insecurity in Nunavut communities worsened after the introduction of the program.

The federal government reports that Nutrition North Canada has been successful in improving food access and affordability, because there was an increase in the volume of perishable, nutritious foods shipped and a decrease in the cost of a standardized food basket soon after Nutrition North Canada was launched compared with the final statistics under the Food Mail Program. ${ }^{34,36}$ However, our findings challenge the assertion that the program has improved food access.

The observed rise in food insecurity also stands in contrast to reports of an increase in the volume of subsidized food shipped under Nutrition North Canada. ${ }^{34,36}$ One possible interpretation for the coexistence of these conflicting trends may be that Nutrition North Canada led to greater consumption of subsidized foods among the most affluent households, while compromising food access among economically vulnerable households because of the removal of the subsidy for common nonperishable foods and essential items. Hence, the retail subsidy and nutrition-education component may have primarily stimulated demand among households that could already afford perishable, nutritious foods. More research is needed to investigate food-access inequality within participating communities to better understand the program's impact.

A primary motivation to replace the Food Mail Program with Nutrition North Canada was to contain program costs..$^{34,35,37-39}$ This was partly achieved by adopting a model that relies on market competition to reduce prices. ${ }^{34,35}$ However, the relevance of this model is highly questionable given that there are few retailers and little competition in most eligible communities, ${ }^{54,55}$ and a substantial portion of the targeted population has difficulty accessing the market economy because of poverty. There is growing evidence that policy interventions improving the economic resources of households through cash transfers or in-kind benefits reduce food insecurity in affluent countries. ${ }^{26-28,58,59}$
Given our results, it is imperative to determine the extent to which similar initiatives adapted to the needs and realities of northern populations could affect food insecurity.

\section{Limitations}

The measure of food insecurity used in this study does not capture all dimensions of food security relevant to Inuit populations (e.g., food-sharing systems and access to traditional food). However, the measure has been associated with poor nutrition and adverse health outcomes among Indigenous populations, including the Inuit. ${ }^{9-11,16}$ The measure is also pertinent to evaluate a program that subsidizes food accessed through the market economy.

Because of the coverage of the survey, the analyses included only the 10 largest communities in Nunavut, and the results may not apply to other eligible communities. However, the communities included in this study comprise a substantial portion of the population targeted by Nutrition North Canada. The few time points available precluded a validation of the linearity assumption $^{45,46}$ for the trends in prevalence of food insecurity for the years before, during and after the implementation of Nutrition North Canada and limited the power of the study, ${ }^{46,47,60}$ which may have contributed to the absence of trends in the prevalence of food insecurity. Although we controlled for several covariates and identified no macroeconomic shocks that coincided with the rise is food insecurity, unobserved time-varying confounding unrelated to the implementation of Nutrition North Canada may still be present. Nevertheless, this study represents an important first step toward understanding the program's impact on food insecurity.

\section{Conclusion}

This evaluation of the impact of Nutrition North Canada suggests that food insecurity has worsened in Nunavut communities after the introduction of the program. Our study raises serious concerns about the federal government's continued focus on 
food-subsidy initiatives to improve food access in the North. Given the important health implications of food insecurity, ${ }^{9-25}$ more effective initiatives are urgently needed to address northern food insecurity.

\section{References}

1. Canadian community health survey, cycle 2.2, nutrition (2004) - income-related household food security in Canada. Ottawa: Office of Nutrition Policy and Promotion, Health Canada; 2007.

2. Gundersen C. Food insecurity is an ongoing national concern. Adv Nutr 2013;4:36-41.

3. Ashton JR, Middleton J, Lang T. Open letter to Prime Minister David Cameron on food poverty in the UK. Lancet 2014;383:1631.

4. Loopstra R, Reeves A, Stuckler D. Rising food insecurity in Europe. Lancet 2015; 385:2041.

5. Tarasuk V, Mitchell A, Dachner N. Household food insecurity in Canada, 2012. Toronto: Research to identify policy options to reduce food insecurity (PROOF); 2014. Available: https://proof.utoronto.ca/resources/proof-annual -reports (accessed 2018 Nov. 28).

6. Monitoring household food insecurity over time. Ottawa: Health Canada; modified 2017 Aug. 8. Available: www.canada.ca/en/health-canada/services/food-nutrition/ food-nutrition-surveillance/health-nutrition-surveys/canadian-community-health -survey-cchs/household-food-insecurity-canada-overview/monitoring-household -food-insecurity-over-time-household-food-insecurity-canada-overview-health -canada.html (accessed 2018 Nov. 28)

7. Council of Canadian Academies. Aboriginal food security in Northern Canada: an assessment of the state of knowledge. Ottawa: The Expert Panel on the State of Knowledge of Food Security in Northern Canada, Council of Canadian Academies; 2014.

8. Tarasuk V, Mitchell A, Dachner N. Household food insecurity in Canada, 2014. Toronto: Research to identify policy options to reduce food insecurity (PROOF); 2016. Available: https://proof.utoronto.ca/resources/proof-annual -reports (accessed 2018 Nov. 28).

9. Huet C, Rosol R, Egeland GM. The prevalence of food insecurity is high and the diet quality poor in Inuit communities. J Nutr 2012;142:541-7.

10. Egeland GM, Johnson-Down L, Cao ZR, et al. Food insecurity and nutrition transition combine to affect nutrient intakes in Canadian Arctic communities. J Nutr 2011;141:1746-53.

11. Egeland GM, Williamson-Bathory L, Johnson-Down L, et al. Traditional food and monetary access to market-food: correlates of food insecurity among Inuit preschoolers. Int J Circumpolar Health 2011;70:373-83.

12. Findlay LC, Langlois KA, Kohen DE. Hunger among Inuit children in Canada. Int J Circumpolar Health 2013;April 23:72.

13. Kirkpatrick SI, Tarasuk V. Food insecurity is associated with nutrient inadequacies among Canadian adults and adolescents. J Nutr 2008;138:604-12.

14. Pirkle CM, Lucas M, Dallaire R, et al. Food insecurity and nutritional biomarkers in relation to stature in Inuit children from Nunavik. Can J Public Health 2014; 105:e233-8.

15. Hackett C, Feeny D, Tompa E. Canada's residential school system: measuring the intergenerational impact of familial attendance on health and mental health outcomes. J Epidemiol Community Health 2016;70:1096-105.

16. Willows N, Veugelers $P$, Raine K, et al. Associations between household food insecurity and health outcomes in the Aboriginal population (excluding reserves). Health Rep 2011;22:15-20.

17. Mclntyre L, Williams JV, Lavorato DH, et al. Depression and suicide ideation in late adolescence and early adulthood are an outcome of child hunger. J Affect Disord 2013;150:123-9.

18. Melchior M, Chastang J-F, Falissard B, et al. Food insecurity and children's mental health: a prospective birth cohort study. PLoS One 2012;7:e52615.

19. Kirkpatrick SI, McIntyre L, Potestio ML. Child hunger and long-term adverse consequences for health. Arch Pediatr Adolesc Med 2010;164:754-62.

20. Jessiman-Perreault G, McIntyre L. The household food insecurity gradient and potential reductions in adverse population mental health outcomes in Canadian adults. SSM Popul Health 2017;3:464-72.

21. Gundersen C, Tarasuk V, Cheng J, et al. Food insecurity status and mortality among adults in Ontario, Canada. PLoS One 2018;13:e0202642.
22. Hajizadeh M, Bombay A, Asada Y. Socioeconomic inequalities in psychological distress and suicidal behaviours among Indigenous peoples living off-reserve in Canada. CMAJ 2019;191:E325-36.

23. Tarasuk V, Cheng J, Gundersen C, et al. The relation between food insecurity and mental health care service utilization in Ontario. Can J Psychiatry 2018;63: 557-69.

24. Tarasuk V, Cheng J, de Oliveira C, et al. Association between household food insecurity and annual health care costs. CMAJ 2015;187:E429-36.

25. Fitzpatrick T, Rosella LC, Calzavara A, et al. Looking beyond income and education: socioeconomic status gradients among future high-cost users of health care. Am J Prev Med 2015;49:161-71.

26. Ionescu-Ittu R, Glymour MM, Kaufman JS. A difference-in-differences approach to estimate the effect of income-supplementation on food insecurity. Prev Med 2015;70:108-16.

27. McIntyre L, Dutton DJ, Kwok C, et al. Reduction of food insecurity among lowincome Canadian seniors as a likely impact of a guaranteed annual income. Can Public Policy 2016;4:274-86.

28. Loopstra R, Dachner N, Tarasuk V. An exploration of the unprecedented decline in the prevalence of household food insecurity in Newfoundland and Labrador, 2007-2012. Can Public Policy 2015;41:191-206.

29. McIntyre L, Wu X, Fleisch VC, et al. Homeowner versus non-homeowner differences in household food insecurity in Canada. J Housing Built Environ 2015;31: 349-66.

30. Smith MD, Rabbitt MP. Coleman- Jensen A. Who are the world's food insecure? New evidence from the Food and Agriculture Organization's Food Insecurity Experience Scale. World Dev 2017;93:402-12.

31. Loring PA, Gerlach SC. Searching for progress on food security in the north American North: a research synthesis and meta-analysis of the peer-reviewed literature. Arctic 2015;68:380-92.

32. Chan HM, Fediuk K, Hamilton S, et al. Food security in Nunavut, Canada: barriers and recommendations. Int J Circumpolar Health 2006;65:416-31.

33. Duhaime G, Bernard N. Arctic food security. Edmonton: The University of Alberta Press; 2008.

34. Implementation evaluation of the Nutrition North Canada Program. Ottawa: Indigenous and Northern Affairs Canada; 2013.

35. From Food Mail to Nutrition North Canada: report of the Standing Committee on Aboriginal Affairs and Northern Development. Ottawa: House of Commons Canada; 2011.

36. Nutrition North Canada [website]. Government of Canada; modified 2019 Apr. 4. Available: www.nutritionnorthcanada.gc.ca/eng/1415385762263/1415385790537 (accessed 2018 Nov. 28).

37. Food Mail review: interim report. Ottawa: Indigenous and Northern Affairs Canada; 2009.

38. Summative evaluation of INAC's Food Mail Program. Ottawa: Indigenous and Northern Affairs Canada; 2009.

39. Dargo G. Food Mail Program review: findings and recommendations of the Minister's Special Representative. Yellowknife: [prepared by] Dargo and Associates; 2008. Available: http://caid.ca/FoodMailRev123108.pdf (accessed 2018 Nov. 28).

40. Performance measurement strategy: (4.1.2) Nutrition North Canada. Ottawa: Government of Canada; 2016.

41. Canadian Community Health Survey - annual component (CCHS). Ottawa: Statistics Canada; modified 2018 Nov. 18. Available: www23.statcan.gc.ca/imdb/ p2SV.pl?Function=getSurvey\&SDDS=3226 (accessed 2018 Nov. 28).

42. Coleman-Jensen A, Rabbitt MP, Gregory C, et al. Household food security in the United States in 2016. Washington (DC): Economic Research Service, US Department of Agriculture; 2017.

43. National Research Council. Food insecurity and hunger in the United States: an assessment of the measure. Washington (DC): The National Academies Press; 2006.

44. Coleman-Jensen AJ. US food insecurity status: toward a refined definition. Soc Indic Res 2010;95:215-30.

45. Bickel G, Nord M, Price C, et al. Guide to measuring household food security, revised 2000. Alexandria (VA): Food and Nutrition Service, United States Department of Agriculture; 2000.

46. Kontopantelis E, Doran T, Springate DA, et al. Regression based quasiexperimental approach when randomisation is not an option: interrupted time series analysis. BMJ 2015;350:h2750. 
47. Bernal JL, Cummins S, Gasparrini A. Interrupted time series regression for the evaluation of public health interventions: a tutorial. Int J Epidemiol 2017;46:348-55.

48. Linden A, Adams JL. Applying a propensity score-based weighting model to interrupted time series data: improving causal inference in programme evaluation. J Eval Clin Pract 2011;17:1231-8.

49. Wagner AK, Soumerai SB, Zhang F, et al. Segmented regression analysis of interrupted time series studies in medication use research. J Clin Pharm Ther 2002;27:299-309.

50. Sriram U, Tarasuk V. Economic predictors of household food insecurity in Canadian metropolitan areas. J Hunger Environ Nutr 2016;11:1-13.

51. Nord M, Coleman-Jensen A, Gregory C. Prevalence of US food insecurity is related to changes in unemployment, inflation, and the price of food. Washington (DC): Economic Research Service, United States Department of Agriculture; 2014.

52. Bartfeld J, Dunifon R. State-level predictors of food insecurity among households with children. J Policy Anal Manage 2006;25:921-42.

53. 2014 fall report of the Auditor General of Canada. Ottawa: Office of the Auditor General of Canada; 2014.
54. Galloway T. Canada's northern food subsidy Nutrition North Canada: a comprehensive program evaluation. Int J Circumpolar Health 2017;76:1279451.

55. Burnett K, Skinner K, LeBlanc J. From Food Mail to Nutrition North Canada: reconsidering federal food subsidy programs for northern Ontario. CFS 2015;2: 141-56.

56. Niqittiavak Committee. The Nutrition North Canada Program. Nunavut: Nunavut Food Security Coalition; 2015.

57. Is Nutrition North Canada on shifting ground? Mississauga (ON): Food Banks Canada; 2016.

58. Loopstra R, Reeves A, McKee M, et al. Food insecurity and social protection in Europe: quasi-natural experiment of Europe's great recessions 2004-2012. Prev Med 2016;89:44-50.

59. Schmidt L, Shore-Sheppard L, Watson T. The effect of safety net programs on food insecurity. J Hum Resour 2016;51:589-614.

60. Craig P, Katikireddi SV, Leyland A, et al. Natural experiments: an overview of methods, approaches, and contributions to public health intervention research. Annu Rev Public Health 2017;38:39-56.
Competing interests: Andrée-Anne Fafard St-Germain and Valerie Tarasuk report grants from the Canadian Institutes of Health Research (CIHR) during the conduct of the study. No other competing interests were declared.

This article has been peer reviewed.

Affiliations: Department of Nutritional Sciences (Fafard St-Germain, Tarasuk), University of Toronto, Toronto, Ont.; Department of Anthropology (Galloway), University of Toronto Mississauga, Mississauga, Ont.

Contributors: Andrée-Anne Fafard St-Germain and Valerie Tarasuk conceptualized and designed the study. Andrée-Anne Fafard St-Germain analyzed the data. Andrée-Anne Fafard St-Germain, Tracey Galloway and Valerie Tarasuk interpreted the results and wrote the paper. All authors approved the final version to be published and agreed to be accountable for all aspects of the work.
Funding: This work was supported by a Programmatic Grant in Health and Health Equity from CIHR (FRN 115208). The funding agency had no role in the study design, data analysis, data interpretation or writing of the report.

Acknowledgement: The analyses presented in this paper were conducted at Statistics Canada's Toronto Research Data Centre at the University of Toronto, which is part of the Canadian Research Data Centre Network. The authors thank the Canadian Research Data Centre Network for facilitating access to the data.

Accepted: Apr. 18, 2019

Correspondence to: Andrée-Anne Fafard St-Germain, andreeanne.fafardst.germain@mail.utoronto.ca 